Bull. Chem. Soc. Ethiop. 2013, 27(1), 57-68.

Printed in Ethiopia

ISSN 1011-3924

DOI: http://dx.doi.org/10.4314/bcse.v27i1.6

(c) 2013 Chemical Society of Ethiopia

\title{
SYNTHESIS OF THERMALLY STABLE METAL SUBSTITUTED HYDROXY APATITES FOR THE SELECTIVE OXIDATION OF LIGHT PARAFFINS
}

\author{
Sooboo Singh and Sreekanth B. Jonnalagadda* \\ School of Chemistry \& Physics, College of Agriculture, Engineering and Science, University of \\ KwaZulu-Natal, Westville Campus, Chiltern Hills, Durban 4000, South Africa
}

(Received October 14, 2011; revised August 9, 2012)

\begin{abstract}
Hydroxyapatite and a series of hydroxyapatite-type compounds containing $\mathrm{Co}, \mathrm{Fe}$ or $\mathrm{Sr}$ were synthesized by co-precipitation and characterized by ICP-OES, BET, IR, Raman spectroscopy, powder and in-situ XRD, SEM, TEM, TPR, TPD and TGA. In-situ XRD and TGA studies indicate that the materials are able to maintain their structure at temperatures reaching $900{ }^{\circ} \mathrm{C}$. The TPD data indicated that acidic sites of varying strengths were present in all the three hydroxyapatites. From SEM, the surface of the materials consisted of an agglomeration of irregular plate-like particles. The catalytic activity of the compounds was investigated in the oxidation of $n$-pentane and $n$-hexane. The conversion of the feed and composition of the products were largely influenced by changes in the temperature and flow rates. For $n$-pentane, the products consisted of lower hydrocarbons and oxygenated compounds, carbon oxides and very small amounts 1,3-pentadiene, furan and furfural. Low conversions of $n$-hexane were obtained for all the tested catalysts and selective products were the hexene isomers and some aromatics.
\end{abstract}

KEY WORDS: Hydroxyapatite, Selective oxidation of $n$-pentane and $n$-hexane, Characterization, Oxygenates, Olefins

\section{INTRODUCTION}

Hydroxyapatite (HAp) is the main component of hard tissues such as bone and teeth. It has the general formula, $\left[\mathrm{Ca}_{10-x}\left(\mathrm{HPO}_{4}\right)_{x}\left(\mathrm{PO}_{4}\right)_{6-x}(\mathrm{OH})_{2-x} 0 \leq x \leq 1\right]$. Stoichiometric HAp has $x=0$ to give $\mathrm{Ca}_{10}\left(\mathrm{PO}_{4}\right)_{6}(\mathrm{OH})_{2}$, whereas for calcium deficient non-stoichiometric hydroxyapatite, $0 \leq x \leq 1[1]$. Hydroxyapatites have found wide applications as materials in bio-ceramics, adsorbents, catalysts and catalyst support materials [2]. They are bi-functional materials with both acidic and basic sites in the crystal lattice and has a hexagonal structure made up from columns of calcium ions and oxygen atoms that are located parallel to the hexagonal axis [3-5]. Three oxygen atoms from each $\mathrm{PO}_{4}$ tetrahedron are shared by one column and the fourth oxygen atom is attached to the neighboring column. The structure of HAp can also be described as a stack of phosphate groups forming two types of tunnels parallel to the $c$-axis [6-14]. The first tunnel is occupied by $\mathrm{Ca}^{2+}$ ions, whereas the second one which is lined by other $\mathrm{Ca}^{2+}$ ions and oxygen is occupied by hydroxideions. The diameter of such tunnels, $3 \AA$ in the case of HAp gives them ion-exchange properties and can also act as a host to small molecules which can alter its crystallinity and morphology without interfering with its hexagonal structure [15].

As a catalyst, HAp was reported to be efficient in the catalytic dehydrogenation and dehydration of alcohols and the direct synthesis of $n$-butanol from ethanol [16-18]. Other studies show that calcium ions in the lattice can be replaced with other cations. The charge compensation mechanism has a major influence on the apatite structure if the charge of the substituting cation is different from that of the $\mathrm{Ca}^{2+}$ ions. Large divalent cations, e.g., $\mathrm{Pb}^{2+}$ replace $\mathrm{Ca}^{2+}$ at calcium II sites whereas small divalent cations, e.g., $\mathrm{Zn}^{2+}$ replace $\mathrm{Ca}^{2+}$ at calcium I sites. Small cations such as $\mathrm{Ni}^{2+}$ and $\mathrm{Co}^{2+}$ can replace $\mathrm{Ca}^{2+}$ at calcium II sites but this has a destabilizing effect on the apatite structure. Several mechanisms have been proposed for the replacement of calcium in HAp by other metal ions, namely, ion exchange, ion adsorption,

*Corresponding author. E-mail: jonnalagaddas@ukzn.ac.za 
dissolution of HAp followed by deposition of a new phase or a combination of these methods $[3,4,19,20]$. Cobalt-exchanged hydroxyapatite was used by Opre et al. [21] in the epoxidation of styrene. Analysis of the liquid phase removed from the reactor revealed formation of styrene oxide and benzaldehyde as the main products along with minors such as phenyl glycol, benzoic acid and phenylacetaldehyde. After two hours of reaction, there was a conversion of $83 \%$ styrene with an epoxide selectivity of $62 \%$. Opre et al. [22, 23] also studied the selective oxidation of alcohols with oxygen on cobalt promoted ruthenium-hydroxyapatite. Earlier, hydroxyapatites were used as supports in a many studies [24-28]. Recently, our group has also successfully used cobalt, iridium and platinum hydroxyapatites as catalysts for solvent-free Knoevenagel condensation reactions of aldehydes with esters, resulting in good yields [29, 30]. In this communication we report the synthesis of $\mathrm{Fe}$, Co or $\mathrm{Sr}$ containing hydroxyapatites and their characterization by various techniques, to determine their potential as support materials. We also report the catalytic activity of these materials in the gas phase oxidation of light paraffins.

\section{EXPERIMENTAL}

Synthesis of hydroxyapatites

All the chemicals used in the preparation of the catalysts were purchased from Merck, Darmstadt, Germany. Hydroxyapatite and the substituted hydroxyapatites were prepared using the methods of Yasukawa et al. [31] and Gibson et al. [32]. In a typical method for the preparation of HAp, aqueous $\mathrm{NH}_{3}$ was added to a $60 \mathrm{~mL}$ solution of $\mathrm{Ca}\left(\mathrm{NO}_{3}\right)_{2} \cdot 4 \mathrm{H}_{2} \mathrm{O}\left(6.67 \times 10^{-}\right.$ $\left.{ }^{2} \mathrm{~mol}\right)$ to elevate the $\mathrm{pH}$ to 11 . The solution was then diluted to $120 \mathrm{~mL}$ with distilled water. A $100 \mathrm{~mL}$ solution of $\left(\mathrm{NH}_{4}\right)_{2} \mathrm{HPO}_{4}\left(4.00 \times 10^{-2} \mathrm{~mol}\right)$ was also adjusted to $\mathrm{pH} 11$ and diluted to 160 $\mathrm{mL}$. The phosphate solution was added to the calcium solution dropwise over a period of 30 minutes at room temperature. A gelatinous precipitate formed which was stirred and boiled for $10 \mathrm{~min}$. After filtration, the precipitate was washed thoroughly with distilled water and dried in an oven set at $100{ }^{\circ} \mathrm{C}$ overnight, thereafter calcined at $500{ }^{\circ} \mathrm{C}$. The other compounds were also prepared using a similar procedure.

\section{Characterization of catalyst materials}

The Brunauer, Emmett and Teller (BET) surface area was estimated out by degassing the catalysts under $\mathrm{N}_{2}$ flow overnight at $250{ }^{\circ} \mathrm{C}$ using a Micrometrics Flow Prep 060. The degassed samples were analyzed in the Micrometrics Gemini 2360 (Micrometrics, USA), fully automatic, multi-point BET surface area analyzer under liquid $\mathrm{N}_{2}$. Inductively coupled plasma (ICP) was performed using a Perkin Elmer Optical Emission Spectrometer Optima 5300 DV to determine the elemental composition of the materials. Standards (1000 ppm Ca, Sr, Co, Fe and P) were purchased from Fluka.

The phases of the catalysts were observed using powder X-ray diffraction (XRD) conducted on a Bruker D8 Advance instrument, equipped with a XRK 900 reaction chamber, a TCU 750 temperature control unit and a $\mathrm{Cu}$ radiation source with a wavelength of 1.5406 . In-situ XRD diffractograms were obtained at $50{ }^{\circ} \mathrm{C}$ intervals from room temperature to $650{ }^{\circ} \mathrm{C}$ for analysis under air flowing at $20 \mathrm{~mL} / \mathrm{min}$. For reduction, temperature conditions were the same except for a $30 \mathrm{~mL} / \mathrm{min}$ hydrogen flow rate.

Infrared (IR) spectra were obtained using a Perkin Elmer Precisely Universal Attenuated Total Reflectance (ATR) sampling accessory equipped with a diamond crystal. The powdered sample was placed on the crystal and a force was applied to ensure proper contact between the sample and the crystal. The spectra were edited and analyzed using Spectrum 100 software. 
Raman spectroscopy was carried out using Advantage 532 series Near Infrared (NIR) Spectrometer utilizing Nuspec software.

Ammonia temperature programmed desorption (TPD) and temperature programmed reduction (TPR) were carried out using a Micromeritics 2920 Autochem II Chemisorption Analyzer. In the TPD experiments, the temperature was set at $950{ }^{\circ} \mathrm{C}$ by means a temperature ramp of $10{ }^{\circ} \mathrm{C} / \mathrm{min}$ using helium gas as carrier flowing at $60 \mathrm{~mL} / \mathrm{min}$. Prior to the reduction of the sample in TPR, the catalyst was pretreated by heating under a stream of argon $(30 \mathrm{~mL} / \mathrm{min})$ at $400{ }^{\circ} \mathrm{C}$ for $30 \mathrm{~min}$ and then cooled to $80{ }^{\circ} \mathrm{C}$. Thereafter, $5 \%$ hydrogen in argon was used as a reducing agent at a flow rate of $30 \mathrm{~mL} / \mathrm{min}$. Under these conditions the temperature was ramped up to $950{ }^{\circ} \mathrm{C}$.Thermogravimetric analysis (TGA) was obtained using a SDT Q600 TA Instrument. Samples were analyzed from $0{ }^{\circ} \mathrm{C}$ to $1000{ }^{\circ} \mathrm{C}$ using a ramp rate of $20{ }^{\circ} \mathrm{C}$ per min under static air.

The surface morphology of the catalysts was obtained by scanning electron microscopy (SEM) utilizing a Leo 1450 Scanning Electron Microscope. Prior to SEM analysis, the samples were mounted on aluminum using double-sided carbon tape and subsequently gold spluttered using the Polaron E5100 coating unit. Transmission electron microscopy (TEM) images and selected area electron diffraction (SAED) patterns for the catalyst samples were viewed on a Jeol JEM-1010 electron microscope. The images were captured and analyzed using $i$ TEM software.

\section{Catalyst testing}

Gas phase oxidation reactions were carried out in a continuous, fixed bed tubular stainless steel microreactor (10 $\mathrm{mm}$ diameter and $300 \mathrm{~mm}$ length). The catalyst bed $(2 \mathrm{~mL})$ was located at the center of the reactor with carborundum packed in the spaces on either side of the bed. The reactor was heated in an electrical furnace. K-type thermocouples were used to monitor the temperature of the catalyst bed and the furnace. The thermocouples were controlled by CB-100 RK Temperature Control Units. The product stream was analyzed by Gas Chromatograph (Varian Star 3400) equipped with a FID module and GC-MS (Finnigan MAT GCQ) using capillary columns (J\&W HP5-MS, $250 \mu \mathrm{m}$ diameter). The carbon oxides and light organic compounds were continuously monitored by a TCD Gas Chromatograph (Buck Scientific, SRI Instruments, USA) using a packed column (6'silica gel/6' molecular sieve). The selectivity was calculated from the conversion of $n$-pentane and $n$-hexane to every product on the basis of the number of carbons.

\section{RESULTS AND DISCUSSION}

\section{Brunauer, Emmett and Teller (BET) surface area and elemental analysis}

The surface areas and the $M / P$ ratios for the catalysts are shown in Table 1 . BET surface area measurements shows that the surface area of the metal hydroxyapatites depends on the type and the crystal structure of the metal. It can be noted that as density of carboxyl group increases the particle size decreases and surface area increases. HAp has the high surface area and low particle size whereas Sr-HAp has the similar particle size but very low surface area. Co-HAp has the lowest surface area as it contains larger particle sizes. The $M / P$ ratio obtained from inductively coupled plasma (ICP) analysis indicates that the hydroxyapatites prepared are in agreement with the stoichiometric ratio of the hydroxyapatite and there is correlation when compared to energy-dispersive X-ray spectroscopy (EDX) measurements. 
Table 1. Brunauer, Emmett and Teller (BET) surface areas and elemental composition.

\begin{tabular}{|l|c|c|c|c|}
\hline Compound & Surface area $\left(\mathrm{m}^{2} / \mathrm{g}\right)$ & Pore volume $\left(\mathrm{m}^{2} / \mathrm{g}\right)$ & ${ }^{\mathrm{a}} M / P$ & ${ }^{\mathrm{b}} M / P$ \\
\hline HAp & 72.5 & 0.2385 & 1.67 & 1.65 \\
\hline Sr-HAp & 17.5 & 0.1366 & 1.66 & 1.67 \\
\hline Co-HAp & 11.5 & 0.0416 & 1.64 & 1.64 \\
\hline Fe-HAp & 30.2 & 0.0113 & 1.65 & 1.65 \\
\hline
\end{tabular}

$M=\mathrm{Ca}, \mathrm{Sr}, \mathrm{Co}$ and $\mathrm{Fe} ;{ }^{\mathrm{a}} M / P$ ratio obtained from ICP; ${ }^{\mathrm{b}} M / P$ ratio obtained from EDX.

Powder and in-situ X-ray diffraction

The XRD patterns of HAp, Sr-HAp, Co-HAp and Fe-HAp(Figure 1) confirm the existence of apatite structure with a single phase that match well with the phases reported in literature [33]. The observed positions of the diffraction lines ( $2 \theta$ and $\mathrm{d}$ values) correspond to the Joint Committee on Powder Diffraction Standards (JCPDS) file no:9-432. HAp and Sr-HAp gives a high number of counts and sharp peaks in XRD which results in smaller crystallite size than CoHAp and Fe-HAp. The crystalline nature of the hydroxyapatites decreases in the order $\mathrm{Fe}, \mathrm{Sr}$ and $\mathrm{Co}$ (Table 2) which is corroborated by the selected area electron diffraction (SAED) images (Figure 2). From the in-situ patterns (Figure 3), we observe that all the materials show no phase change and are very stable at high temperatures, even in the reduction and oxidation atmospheres.

Table 2. Particle size and crystallinityof hydroxyapatites.

\begin{tabular}{|l|c|c|c|}
\hline \multirow{2}{*}{ Compound } & Crystallite & size & \multirow{2}{*}{ Crystallinity $^{b}$} \\
\cline { 2 - 3 } & XRD $^{a}$ & TEM & \\
\hline HAp & 3.17 & 3.21 & 0.795 \\
\hline Sr-HAp & 3.81 & 3.79 & 0.702 \\
\hline Co-HAp & 5.53 & 5.21 & 0.215 \\
\hline Fe-HAp & 4.83 & 4.75 & 0.794 \\
\hline
\end{tabular}

${ }^{\mathrm{a}}$ Calculated by Scherer's equation. ${ }^{\mathrm{b}} \mathrm{X}_{\mathrm{c}}=1-\left(\mathrm{V}_{112 / 300} / \mathrm{I}_{300}\right), \mathrm{X}_{\mathrm{c}}$ is degree of crystallinity, $\mathrm{V}_{112 / 300}$ is the intensity of the shoulder between (112) and (300) diffraction peaks and $\mathrm{I}_{300}$ is the intensity of the (300) peak.

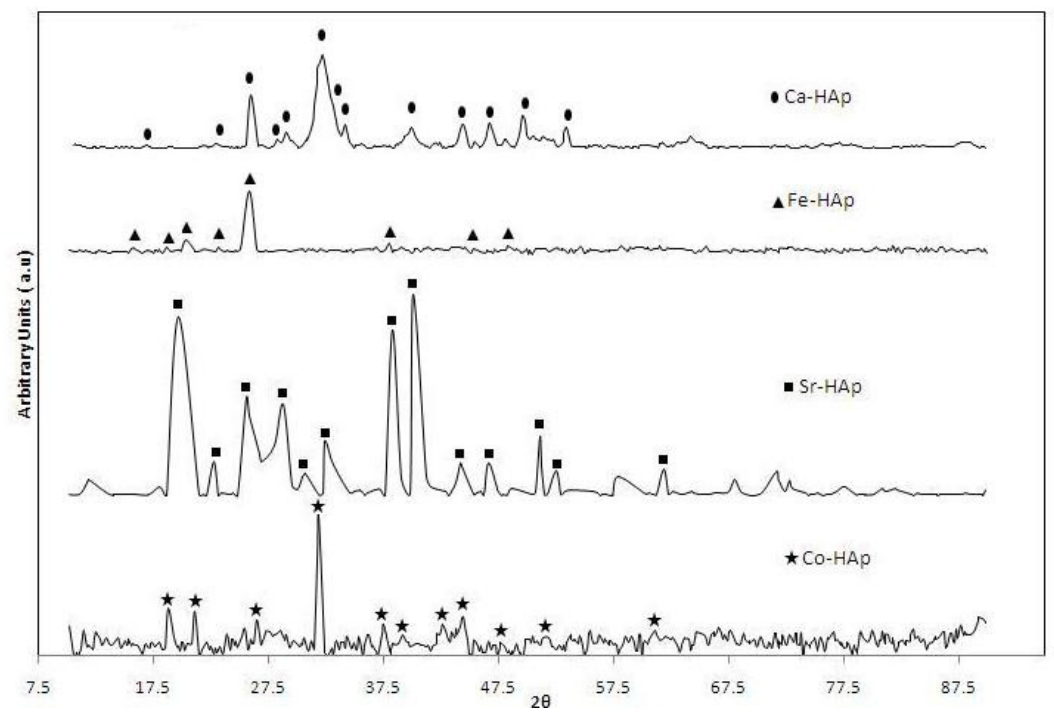

Figure 1. XRD patterns of (a) Co-HAp, (b) Sr-HAp, (c) Fe-HAp and (d) Ca-Hap.

Bull. Chem. Soc. Ethiop. 2013, 27(1) 

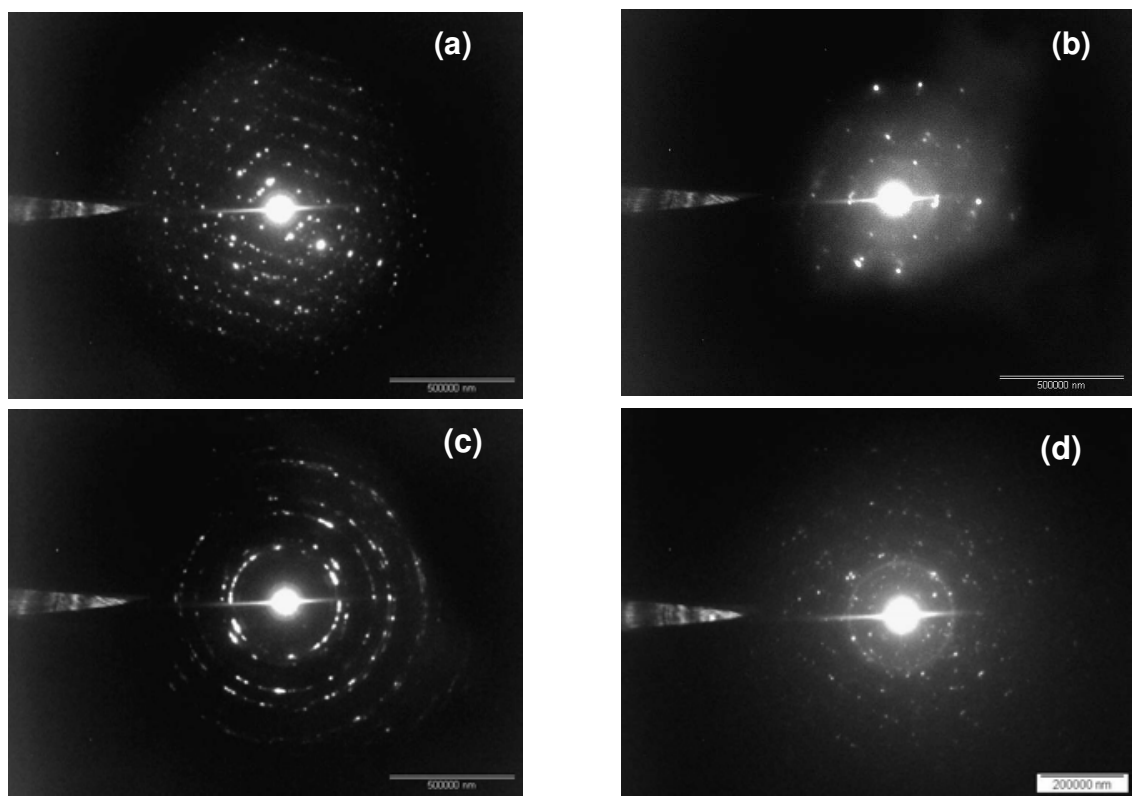

Figure 2. Selected area electron diffraction (SAED) images of (a) Co-HAp, (b) Sr-HAp, (c) FeHAp and (d) Hap.

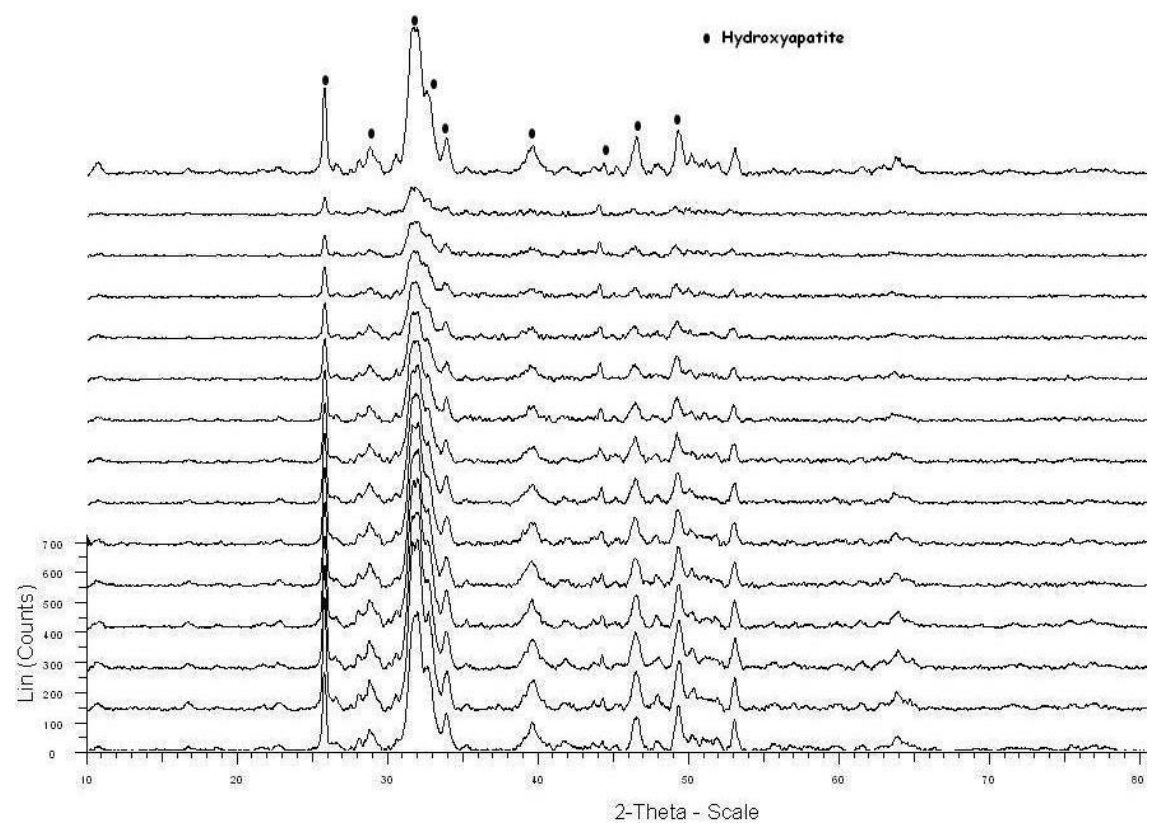

Figure 3. In-situ XRD diffractograms of HAp after reduction under hydrogen and re-oxidation.

Bull. Chem. Soc. Ethiop. 2012, 26(3) 


\section{Infrared spectroscopy}

The infrared (IR) spectroscopic investigations of the materials show the characteristic bands for the hydroxyapatite compounds and agrees with literature $[33,34]$. Bands at $1612-1624 \mathrm{~cm}^{-1}$ are assigned to the bending mode of water and the peak between $630-665 \mathrm{~cm}^{-1}$ is the result of the presence of the $\mathrm{OH}$ group of HAp. The spectral features between 900 and $1200 \mathrm{~cm}^{-1}$ arise primarily from the symmetric $v_{1}$ and asymmetric $v_{3} \mathrm{P}-\mathrm{O}$ stretching modes of the phosphate groups. Under strict tetrahedral symmetry for orthophosphate, $v_{1}$ is IR inactive. However, when the symmetry in the crystal is lowered from that of the free ion, the symmetric stretch appears as a weak feature in the IR spectra region, $950-970 \mathrm{~cm}^{-1}$. The $v_{3}$ mode is triply degenerate in the free ion and may resolve into three separate modes when the degeneracy is lifted. We therefore expect that on analysis of $900-1200 \mathrm{~cm}^{-1}$ region would lead to multiple bands arising from both the phosphate $v_{1}$ and $v_{3}$ modes.

Bands in the $500-700 \mathrm{~cm}^{-1}$ region arise primarily from the asymmetric $\mathrm{P}-\mathrm{O}$ bending modes of the phosphate groups. The weak absorbance band at $870 \mathrm{~cm}^{-1}$ is attributed to the $v_{2}$ mode of carbonate which may be incorporated into the apatites from atmospheric $\mathrm{CO}_{2}$. In Fe-HAp, the strong peak at $575 \mathrm{~cm}^{-1}$ and a medium peak at $425 \mathrm{~cm}^{-1}$ are due to the presence of ferrate in the hydroxyapatite, whereas in Co-Hap, the presence of cobalt is indicated by a medium peak at 626 $\mathrm{cm}^{-1}$ and a strong peak at $569 \mathrm{~cm}^{-1}$. In Sr-HAp, the peaks at $325 \mathrm{~cm}^{-1}$ and $260 \mathrm{~cm}^{-1}$ are due to the vibrations of the bond between strontium and to the phosphate.

\section{Raman spectroscopy}

Raman spectra (Figure 4) of hydroxyapatites are usually characterized by a strong band at 956 $\mathrm{cm}^{-1}$, which is a result of the symmetric stretching mode of the phosphate group. In addition, other Raman-active bands were observed at $1040 \mathrm{~cm}^{-1}, 590 \mathrm{~cm}^{-1}$ and $435 \mathrm{~cm}^{-1}$. The position of the phosphate anion is dependent on the metal present in the hydroxyapatite. A symmetric P-O stretching band is observed at $938 \mathrm{~cm}^{-1}$ and symmetric O-P-O bending at $420 \mathrm{~cm}^{-1}$, whereas an asymmetric P-O stretching band is observed at $1017 \mathrm{~cm}^{-1}$ and asymmetric O-P-O bending at 567 $\mathrm{cm}^{-1}$. The internal Raman vibrations of phosphate and hydroxyl ions in apatite appear above 400 $\mathrm{cm}^{-1}$. Bands below these values are classified as lattice (external) modes.

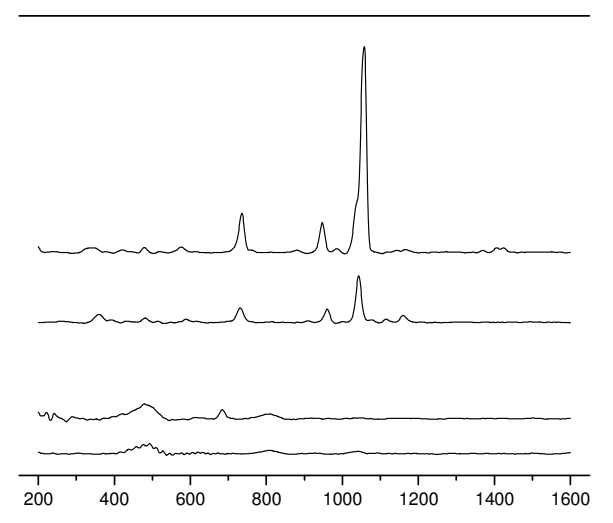

Figure 4. Raman spectra of hydroxyapatites. 


\section{Temperature programmed reduction and desorption}

The temperature programmed reduction (TPR) profiles of the compounds are shown in Figure 5 whereas change in the oxidation state together with the degree of reducibility of the materials is summarized in Table 3. For HAp, the reducibility is very low and very weak signals are observed ( $<0.1$ a.u.) indicating that HAp is stable in reduction atmospheres. Sr-HAp shows reducibility at two temperatures, a minor peak at $496{ }^{\circ} \mathrm{C}$ and a major peak at $579{ }^{\circ} \mathrm{C}$. At the initial stage of reduction a low amount of hydrogen is consumed reducing the $\mathrm{Sr}_{-} \mathrm{O}_{x}$ to an oxidation state of 1.67 at $496{ }^{\circ} \mathrm{C}$. Thereafter, a significant peak at $579{ }^{\circ} \mathrm{C}$ appears on consumption of a large amount of hydrogen resulting in a final oxidation state of +0.5 for $\mathrm{Sr}$. Fe-HAp shows a reduction in oxidation state at the temperature of $517{ }^{\circ} \mathrm{C}$. A small peak at 680 ${ }^{\circ} \mathrm{C}$ is the result of the change in oxidation state of the unreduced portion at the initial peak. Peaks at $800{ }^{\circ} \mathrm{C}$ and $900{ }^{\circ} \mathrm{C}$ are due to the decrease in the oxidation state to less than 1 . While Co-HAp shows three peaks in its TPR profile, all are below $300{ }^{\circ} \mathrm{C}$. The initial peak at $106{ }^{\circ} \mathrm{C}$ is attributed to evolution of hydroxides from the catalyst while the second peak at $192{ }^{\circ} \mathrm{C}$ indicates that the metal is partially reduced under the conditions of TPR. At $240{ }^{\circ} \mathrm{C}$, Co is reduced to an oxidation state of +0.5 .



Figure 5. Temperature programmed reduction (TPR) profiles of (a) Co-HAp, (b) Sr-HAp, (c) FeHAp and (d) Hap.

Table 3. Oxidationstate change and degree of reducibility of hydroxyapatites.

\begin{tabular}{|l|c|c|c|c|}
\hline Compound & Peak temp. $\left({ }^{\circ} \mathrm{C}\right)$ & $\begin{array}{c}\text { Moles } \mathrm{H}_{2} \text { consumed } \\
\left(\mathrm{cm}^{3} / \mathrm{g} \text { STP }\right)\end{array}$ & $\begin{array}{c}\text { Oxidation state } \\
\text { change }\end{array}$ & $\begin{array}{c}\text { Degree of } \\
\text { reducibility }(\%)\end{array}$ \\
\hline \multirow{3}{*}{ HAp } & 534 & 0.198 & +2 to 1.96 & 1.53 \\
\cline { 2 - 5 } & 653 & 2.830 & 1.56 & 21.92 \\
\hline \multirow{3}{*}{ Sr-HAp } & 859 & 0.115 & 1.54 & 0.89 \\
\cline { 2 - 5 } & 496 & 0.130 & 1.67 & 0.89 \\
\hline Fe-HAP & 579 & 0.655 & 0.43 & 16.32 \\
\cline { 2 - 5 } & 518 & 0.820 & 1.02 & 17.06 \\
\cline { 2 - 5 } & 673 & 0.410 & 1.00 & 24.49 \\
\cline { 2 - 5 } & 819 & 0.110 & 0.86 & 3.57 \\
\hline \multirow{3}{*}{ Co-HAp } & 913 & 0.060 & 0.78 & 16.49 \\
\cline { 2 - 5 } & 106 & 0.110 & 1.67 & 17.75 \\
\cline { 2 - 5 } & 192 & 0.190 & 1.31 & 50.03 \\
\hline
\end{tabular}

Bull. Chem. Soc. Ethiop. 2012, 26(3) 
For temperature programmed desorption (TPD), the strength of acid sites is directly related to the desorption temperature. Ammonia is desorbed from weak acid sites below $300{ }^{\circ} \mathrm{C}$, from moderated acid sites between $400{ }^{\circ} \mathrm{C}$ and $450{ }^{\circ} \mathrm{C}$, from strong acid sites between $450{ }^{\circ} \mathrm{C}$ and $650{ }^{\circ} \mathrm{C}$ and from very strong acid sites above $650{ }^{\circ} \mathrm{C}$ for heating rate of $10{ }^{\circ} \mathrm{C} \mathrm{min}{ }^{-1}$. The TPD profiles of the hydroxyapatites and the distribution of acidic sites are displayed in Figure 6 and Table 4, respectively. HAp shows a fair distribution of acidic sites. The peaks at $639{ }^{\circ} \mathrm{C}$ and 679 ${ }^{\circ} \mathrm{C}$ are due to the presence of $\mathrm{Ca}^{+2}$ ions. The very strong acidic sites can be attributed to the protons from $\mathrm{HPO}_{4}{ }^{2-}$ in the sample whereas the shoulder at $725{ }^{\circ} \mathrm{C}$ is due to desorption of ammonia from the solid sample. Co-HAp shows a similar pattern to HAp regarding the distribution of acidic sites whereas moderate to normal sites are present on Fe-HAp. Sr-HAp, on the other hand has a large and broad distribution of acidic sites.

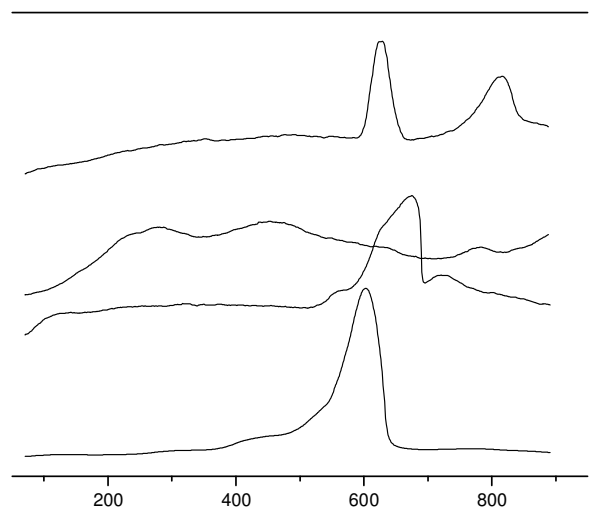

Figure 6. Temperature programmed ammonia desorption (TPD) profiles of hydroxyapatites.

Table 4. Distribution of acidic sites obtained from the temperature programmed ammonia desorption (TPD) data.

\begin{tabular}{|l|c|c|c|c|c|c|}
\hline \multirow{2}{*}{ Compound } & \multicolumn{5}{|c|}{ Acidic sites $(\mu \mathrm{mol} \mathrm{NH} / \mathrm{g})$} & \multirow{2}{*}{$\begin{array}{c}\text { Specific acidity } \\
\left(\mu \mathrm{mol} / \mathrm{m}^{-2}\right)\end{array}$} \\
\cline { 2 - 6 } & Mod. & Norm & Str. & V. Str. & Total & 4 \\
\hline HAp & - & 79 & 103 & 21 & 203 & 2648 \\
\hline Sr-HAp & 7273 & 15900 & 23173 & - & 46345 & 114 \\
\hline Co-HAp & 1728 & 1690 & 46 & - & 3464 & 66 \\
\hline
\end{tabular}

Mod. $=$ moderate, Norm. $=$ normal, Str. $=$ strong, V. Str. $=$ very strong.

\section{Thermogravimetric analysis}

From thermogravimetric analysis (TGA), the thermal decomposition of hydroxyapatite has been proposed to occur as follows:

$$
\begin{aligned}
& \mathrm{Ca}_{10-\mathrm{x}}\left(\mathrm{HPO}_{4}\right)_{\mathrm{x}}\left(\mathrm{PO}_{4}\right)_{6-\mathrm{x}}(\mathrm{OH})_{2-\mathrm{x}} \rightarrow \mathrm{Ca}_{10-\mathrm{x}}\left(\mathrm{P}_{2} \mathrm{O}_{7}\right)_{\mathrm{x}}\left(\mathrm{PO}_{4}\right)_{6-2 \mathrm{x}}(\mathrm{OH})_{2}, 250{ }^{\circ} \mathrm{C} \leq \mathrm{T} \leq 600{ }^{\circ} \mathrm{C} \\
& \mathrm{Ca}_{10-\mathrm{x}}\left(\mathrm{P}_{2} \mathrm{O}_{7}\right)_{\mathrm{x}}\left(\mathrm{PO}_{4}\right)_{6-2 \mathrm{x}}(\mathrm{OH})_{2} \rightarrow(1-\mathrm{x}) \mathrm{Ca}_{10}\left(\mathrm{PO}_{4}\right)_{6}(\mathrm{OH})_{2}+3 \mathrm{x} \beta-\mathrm{Ca}_{3}\left(\mathrm{PO}_{4}\right)_{2}+\mathrm{xH} \mathrm{H}_{2} \mathrm{O}, \mathrm{T}>60{ }^{\circ} \mathrm{C} .
\end{aligned}
$$

The weight loss is differentiated into three regions, $30-250{ }^{\circ} \mathrm{C}, 250-700{ }^{\circ} \mathrm{C}$ and $700-900{ }^{\circ} \mathrm{C}$. In the first region, the weight loss can be attributed to the physically adsorbed water. Mortier et al. [35] reported a severe weight loss between the 350-700 ${ }^{\circ} \mathrm{C}$ temperature range due to the condensation of hydrogen phosphate groups $\left(\mathrm{HPO}_{4}{ }^{2-}\right)$ to form pyrophosphates $\left(\mathrm{P}_{2} \mathrm{O}_{7}\right)^{4-}$ in the calcium deficient apatite. The exothermic process occurring between $550-590{ }^{\circ} \mathrm{C}$ shows crystallization of hydroxyapatite. Further, Brasseur [36] observed a weight loss curve at $800{ }^{\circ} \mathrm{C}$ 
which was attributed to $\mathrm{P}_{2} \mathrm{O}_{4}{ }^{4-}$ converting to $\mathrm{PO}_{4}{ }^{3-}$ ( $\beta$-tricalcium phosphate). The TGA profile of the powders show similar features and is presented in Figure 7. However, in Sr-HAp a severe weight loss occurs in between $450-600{ }^{\circ} \mathrm{C}$ due to the condensation of hydrogen phosphate groups $\left(\mathrm{HPO}_{4}{ }^{2-}\right)$ to form pyrophosphates $\left(\mathrm{P}_{2} \mathrm{O}_{7}\right)^{4-}$ in the strontium deficient apatite.

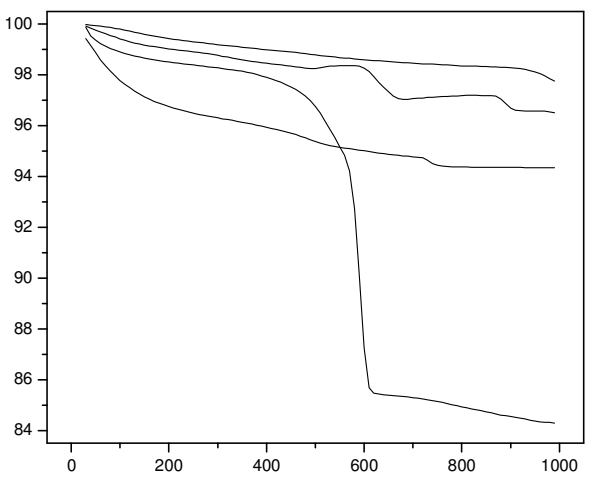

Figure 7. Thermogravimetric analysis (TGA) profiles of hydroxyapatites.

\section{Scanning electron and transmission electron microscopy}

From scanning electron microscopy (SEM) images (Figure 8), an agglomeration of irregular plate-like particles in all the powders was observed. The agglomeration is due to the exposure of the materials to a beam with the high energy resulting in the loss of hydroxyl groups. On high magnification, the irregular shaped particles become clearer and the plates are stacked upon each other. The images of the d-block elements of $\mathrm{Fe}$ and $\mathrm{Co}$ appear brighter due to the penetration of the electrons under the electronic beam. The SEM images suggest that the particles are homogenously prepared and the elemental composition results from energy dispersive X-ray spectroscopy (EDX) compares favorably with the ICP results.

Transmission electron microscopy (TEM) micrographs (Figure 9) show the images of the metal hydroxyapatites after calcination at $550{ }^{\circ} \mathrm{C}$ for $3 \mathrm{~h}$. Calcination is necessary to ensure that the structure of the materials is maintained after being exposed to high intensity electron beams. From the images, all the hydroxyapatite particles are found to have a range in size between the $30-50 \mathrm{~nm}$. From selected area diffraction patterns diffractions spots are observed in the weak ring pattern, confirming the evolution of poly crystalline apatite powders. The diffraction spots appeared to be cleared with changing the primary metal in the hydroxyapatite suggesting the enhanced crystallinity and increased crystallite size.

Catalyzed oxidation of n-pentane and n-hexane

Experiments were carried out at different flow rates over a temperature range of $300-450{ }^{\circ} \mathrm{C}$. Steady state was achieved after $3 \mathrm{~h}$ for each catalytic run. Blank runs carried out with the reactor filled with carborundum, showed negligible activity. The activity increased to about $20 \%$ with the use of hydroxyapatites as catalysts (Figure 10a). The products obtained consisted of lower hydrocarbons and oxygenated compounds, carbon oxides and very small amounts 1,3pentadiene, furan and furfural. A 3.0-6.0\% conversion of $n$-hexane was obtained in the blank runs, when the reactor filled with carborundum. When the hydroxyapatites were used as catalysts, the conversion increased to about $10 \%$ resulting in the formation of a wide range of compounds and carbon oxides (Figure 10b). Small amounts of acetic acid, propanoic acid, a mixture of hexenes, benzene, furan and furfural were also observed in the product stream. 

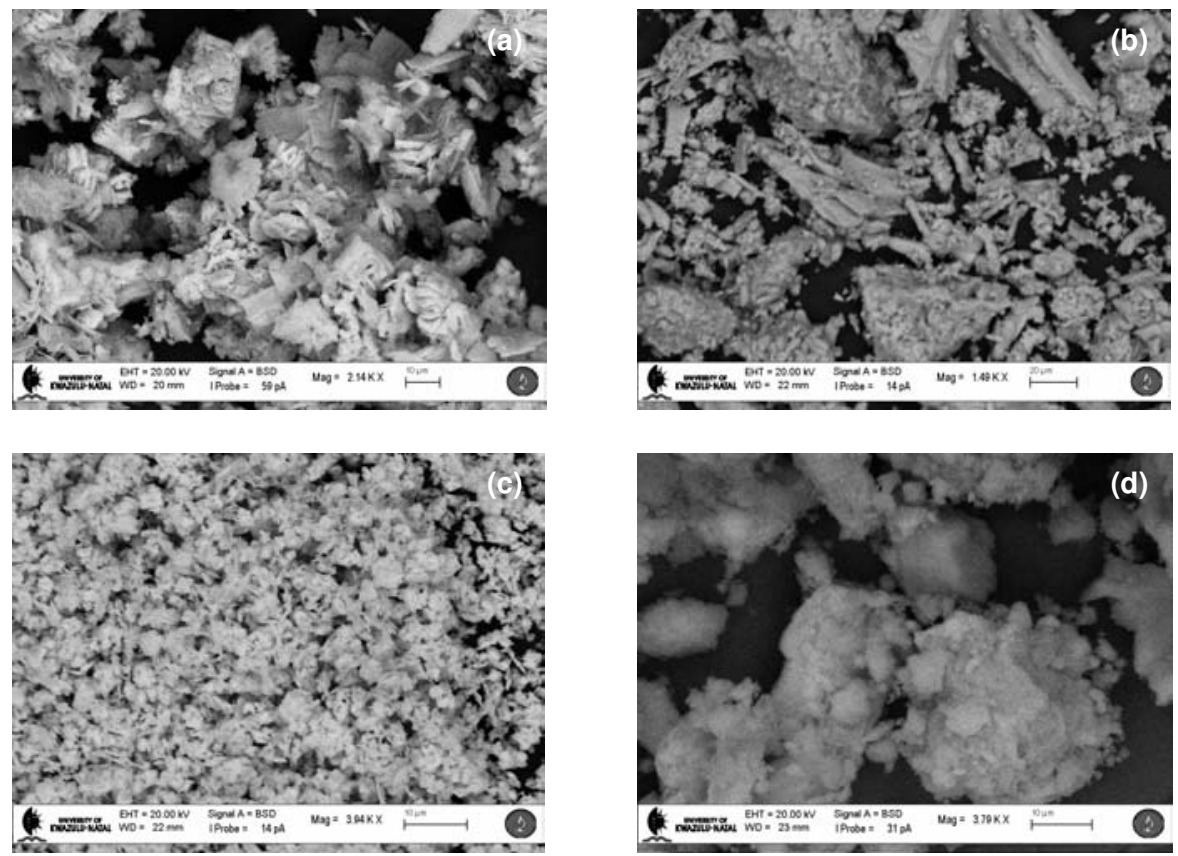

Figure 8. SEM images of (a) Co-HAp, (b) Sr-HAp, (c) Fe-HAp and (d) Hap.
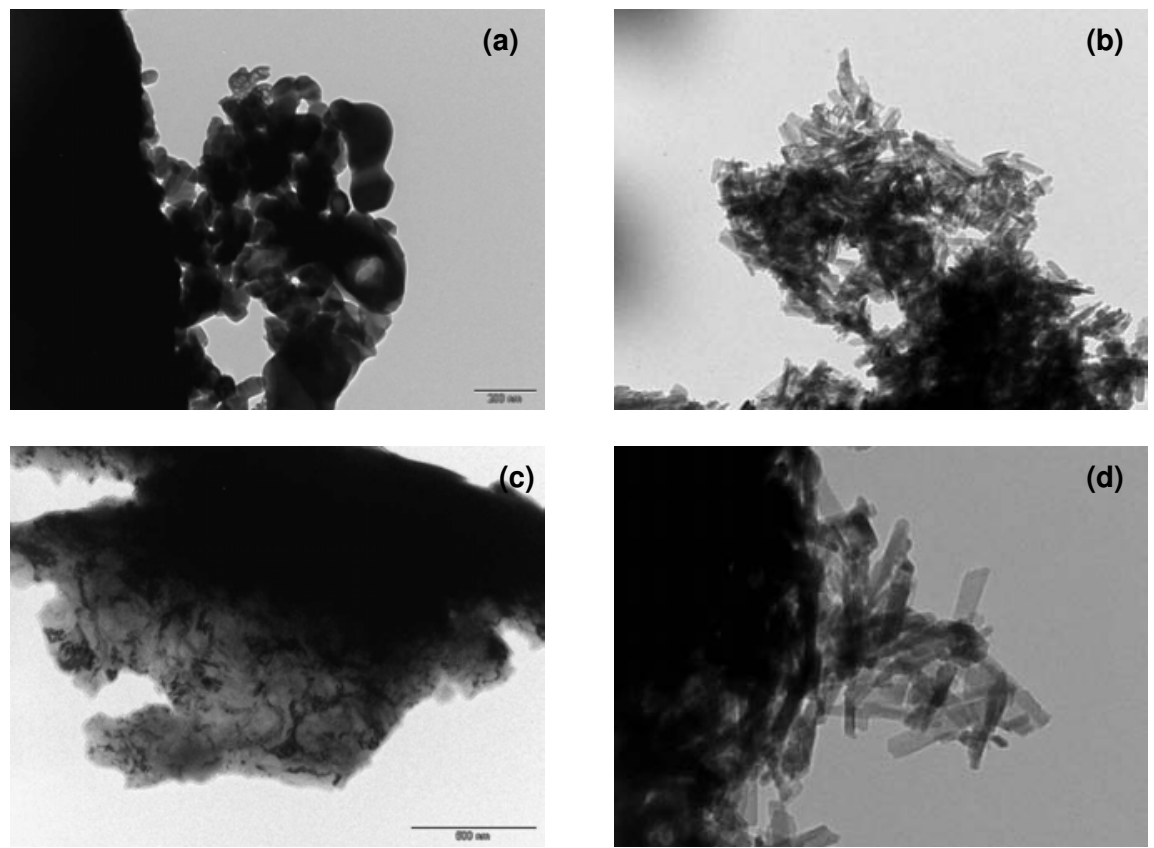

Figure 9. TEM images of (a) Co-HAp, (b) Sr-HAp, (c) Fe-HAp and (d) Hap. Bull. Chem. Soc. Ethiop. 2013, 27(1) 



Figure 10. Conversion of $n$-pentane (a) and $n$-hexane (b) as a function of temperature.

\section{CONCLUSIONS}

From elemental analysis, the $M / P$ ratio of the materials confirms that stoichiometric hydroxyapatites were synthesized. The materials are stable at temperatures reaching $650{ }^{\circ} \mathrm{C}$ as shown by the in-situ XRD patterns where no phase changes were observed, even in the reduction and oxidation atmospheres. Also, the reducibility of the compounds is very low, and very weak signals observed in the TPR profiles indicate that hydroxyapatites are stable in reduction atmospheres. Conversions of $n$-pentane and $n$-hexane were obtained when hydroxyapatites were used as catalysts. The catalytic activity of the hydroxyapatites together with its thermal stability shows that these materials have good potential as catalyst supports.

\section{ACKNOWLEDGEMENTS}

Authors thank the University of KwaZulu-Natal and the National Research Foundation (Thuthuka), Pretoria for financial assistance.

Bull. Chem. Soc. Ethiop. 2012, 26(3) 


\section{REFERENCES}

1. Sugiyama, S.; Miyamoto, T.; Hayashi, H.; Moffat, J.B. J. Mol. Catal. A: Chem. 1998, 135, 199.

2. Jun, J.H.; Lim, T.H.; Nam, S.W.; Hong, S.A.; Yoon, K.J. Appl. Catal. A: Gen. 2006, 312, 27.

3. Opre, Z.; Grunwaldt, J.D.; Maciejewski, M.; Ferri, D.; Mallat, T.; Baiker, A. J. Catal. 2005, 230, 406.

4. Elkabous, K.; Kacimi, M.; Ziyad, M.; Ammar, S.; Bozon-Verduraz, F. J. Catal. 2004, 226, 16.

5. de Leeuw, N.H. Chem. Commun. 2001, 1646.

6. Cazalbou, S.; Combes, C.; Eichert, D.; Rey, C. J. Mater. Chem. 2004, 14, 2148.

7. Rey, C.; Trombe, J.C.; Montel, G. J. Chem. Res. 1978, 2401.

8. Elliot, J.C. in Structure and Chemistry of the Apatites and Other Calcium Orthophosphates, Elsevier Science BV: Amsterdam, The Netherlands; 1994.

9. MacConnel, D. in Apatite, Its Crystal Chemistry, Mineralogy, Utilization and Geologic and Biologic Occurrences, Springer-Verlag: New York; 1973.

10. Heughebaert, J.C.; Montel, G. Calcif. Tissue Int. 1982, 34, 103.

11. Montel, G.; Bonel, G.; Heughebaert, J.C.; Trombe, J.C.; Rey, C. J. Cry. Growth 1981, 53, 74.

12. Baig, A.A.; Fox, J.L.; Young, R.A.; Wang, Z.; Hsu, J.; Higuchi, W.I.; Chettry, A.; Zhuang, H.; Otsuka, M. Calcif. Tissue Int. 1999, 64, 437.

13. Daculsi, G.; Bouler, J.M.; LeGeros, R.Z. Int. Rev. Cytol. 1997, 172, 129.

14. Legros, R.; Balmain, N.; Bonel, G. J. Chem. Res. (S) 1986, 1, 8.

15. Kannan, S.; Ferreira, J.M.F. Chem. Mater. 2006, 18, 198.

16. Kibby, C.L.; Hall,W.K. J. Catal. 1973, 29, 144.

17. Monma, H. J. Catal. 1982, 75, 200.

18. Tsuchida, T.; Sakuma, S.; Takeguchi, T.; Ueda, W. Ind. Eng. Chem. Res. 2006, 45, 8634.

19. Valsami-Jones, E.; Ragnarsdottir, K.V.; Putnis, A.; Bosbach, D.; Kemp, A.J.; Cressey, G. Chem. Geol. 1998, 151, 215.

20. Kay, M.I.; Young, R.A.; Posner, A.S. Nature 1964, 204, 1050.

21. Opre, Z.; Mallat, T.; Baiker, A. J. Catal. 2007, 245, 482.

22. Opre, Z.; Grunwaldt, J.D.; Mallat, T.; Baiker, A. J. Mol. Catal. A: Chem. 2005, 242, 224.

23. Opre, Z.; Ferri, D.; Krumeich, F.; Mallat, T.; Baiker, A. J. Catal. 2006, 241, 287.

24. Yamaguchi, K.; Mori, K.; Mizugaki, T.; Ebitani, K.; Kaneda, K. J. Am. Chem. Soc. 2000, $122,7144$.

25. Mori, K.; Yamaguchi, K.; Hara, T.; Mizugaki, T.; Ebitani, K.; Kaneda, K. J. Am. Chem. Soc. 2002, 124, 11572.

26. Saih, Y.; Chaoui, M.A.; Ezzamarty, A.; Lakdhar, M. Catal. Commun. 2001, 2, 81.

27. Sebti, S.; Tahir, R.; Nazih, R.; Saber, A.; Boulaajaj, S. Appl. Catal. A 2002, 228, 155.

28. Venugopal, A.; Scurrel, M.S. Appl. Catal. A 2003, 245, 137.

29. Pillai, M.K.; Singh, S.; Jonnalagadda, S.B. Synth.Commun. 2010, 41, 3710.

30. Pillai, M.K.; Singh, S.; Jonnalagadda, S.B. Kinet. Catal. 2011, 52, 536.

31. Yasukawa, A.; Kidokoro, M.; Kandoria, K.; Ishikawa,T. J. Colloid Inter. Sc. 1997, 191, 407.

32. Gibson, I.R.; Bonfield, W. J. Mater. Sc.: Mater. Med. 2002, 13, 685.

33. Parhi, P.; Ramanan, A.; Ray, A.R. Mater. Lett. 2006, 60, 218.

34. Chary, K.V.R.; Kishan, G.; Bhaskar, T.; Sivaraj, C. J. Phys. Chem. B 1998, 102, 6792.

35. Mortier, A.; Lemaitre, J.; Roushe, P.G. Thermochim. Acta 1989, 143, 265.

36. Brasseur, H. Bull. Soc. Chim. Belges. 1953, 62, 383.

Bull. Chem. Soc. Ethiop. 2013, 27(1) 